\title{
Spectral Characteristics of the Beam Attenuation Coefficient in the Atlantic Ocean Tropical Area
}

\author{
V.I. Mankovsky, E.V. Mankovskaya* \\ Marine Hydrophysical Institute, Russian Academy of Sciences, Sevastopol, Russian Federation \\ *e-mail:emankovskaya@mail.ru
}

The results of measurements of the $\varepsilon(\lambda)$ beam attenuation coefficient (BAC) spectral distribution in the surface waters of the North Atlantic tropical region (NATR) are represented. The data were obtained in the $27^{\text {th }}$ cruise of R/V Akademik Vernadsky (January - April, 1984).

According to the data of the beam attenuation coefficient spectra measurements in the surface waters of the tropical Atlantic northern part, the characteristics of the spectra (440 - $675 \mathrm{~nm}$ range) were obtained. Also, the change of the spectra shape the in the NATR waters with the attenuation coefficient increase was considered. Spectral distributions of the attenuation coefficient in the waters of the principal large-scale NATR currents and in the coastal African waters are presented. A comparison of the mean spectra in oligotrophic waters of the tropical Atlantic and the Pacific Ocean was carried out. It showed the same pattern of the spectral distribution of the attenuation coefficient in these regions.

For an array of empirical functions $\varepsilon(\lambda)$ in the NATR waters, the expansion into orthogonal eigenvectors was carried out. The possibility to reconstruct the spectra using the first orthogonal vector, i.e. by measuring the attenuation coefficient at one wavelength, is shown. The optimal wavelength values, which should be used to reconstruct the spectra, are indicated.

The relation of the chlorophyll concentration in the surface ocean waters of the NATR with the beam attenuation coefficients in three sections of the spectrum with wavelengths of 440, 500 and $551 \mathrm{~nm}$ was established. In the NATR coastal waters the relation $C_{c h l}=f[\varepsilon(\lambda)]$ should be considered separately, since it differs significantly from the one in ocean waters. The chlorophyll and attenuation coefficient relations in NATR ocean waters established in this work should be characterized as regional.

Keywords: beam attenuation coefficient, spectral characteristics, reconstruction of spectra, chlorophyll concentration

DOI: $10.22449 / 1573-160 X-2017-1-41-52$

(C) 2017, V.I. Man'kovsky, E.V. Man'kovskaya

(C) 2017, Physical Oceanography

\section{Introduction}

A number of studies has been devoted to research of the beam attenuation coefficient $\varepsilon(\lambda)$ in the Atlantic tropical area, but the greatest part of them consider the beam attenuation coefficient in the only one part of the spectrum. The spectral variability of the beam attenuation coefficient $\varepsilon(\lambda)$ in a wide wavelength range is less studied. As an example, the works $[1,2]$ can be provided. The first one demonstrates the results of measuring the spectral distribution of the beam attenuation coefficient within the wavelength range of $\lambda=473 \div 649 \mathrm{~nm}$ in the Sargasso Sea waters [1]. The second article shows the shape of the spectra within the range of $\lambda=400 \div 675 \mathrm{~nm}$ in some currents of the Northern Atlantic tropical region (NATR) [2].

The data obtained in the 27th cruise of R/V Akademik Vernadsky (JanuaryApril, 1984) permit to bridge this gap. Fig. 1 shows the route of the vessel. In this voyage, Numerous measurements of $\varepsilon(\lambda)$ spectra within the wavelength range of 
$\lambda=440 \div 675 \mathrm{~nm}$ in the NATR surface waters were carried out to obtain data on the $\varepsilon(\lambda)$ spectral function structure in vast ocean waters under various oceanographic conditions. Also, these measurements were aimed to study the possibility of reconstructing the $\varepsilon(\lambda)$ spectra from measurements at one wavelength (selfsimilarity of spectra) and the possibility of using attenuation indices for determining the chlorophyll concentration by an optical method.

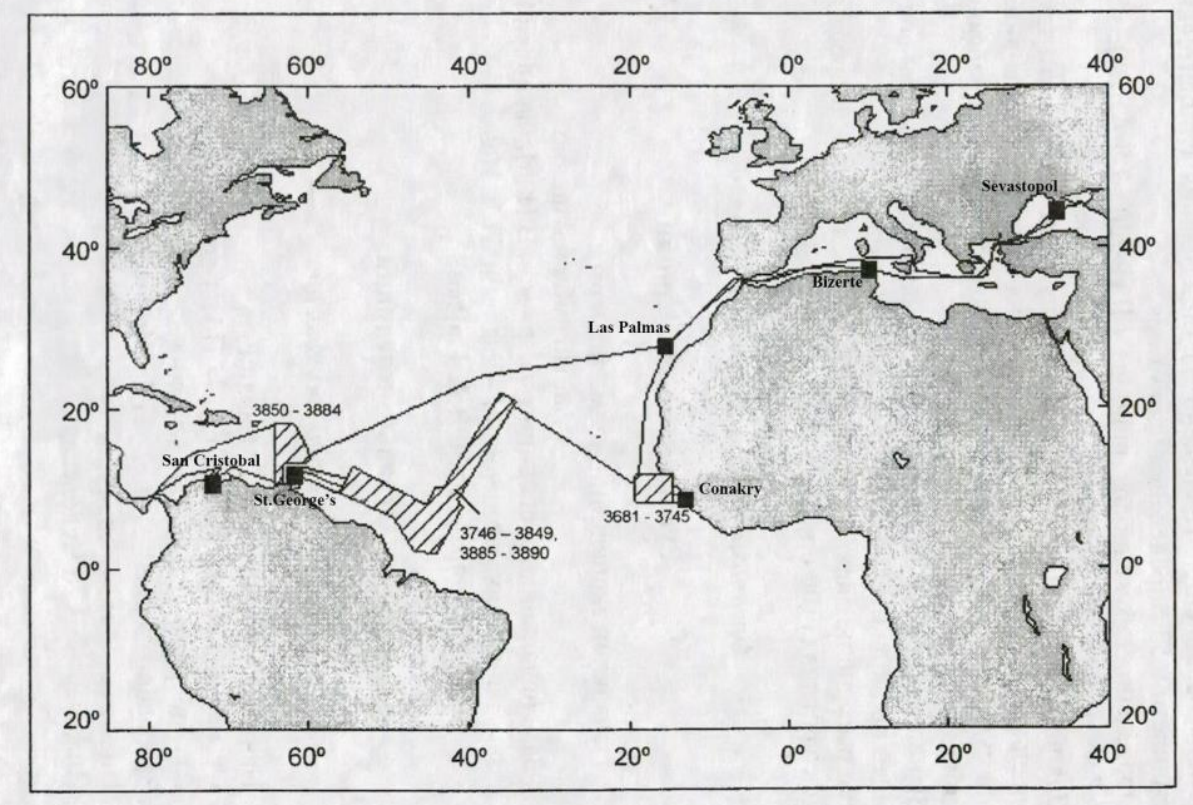

Fig. 1. The route of the 27th cruise of R/V Akademik Vernadsky

\section{Instruments and procedure of measurements}

Measurements of the beam attenuation coefficient $\varepsilon(\lambda)$ were carried out in water samples using a laboratory transparency meter [3] in 12 spectral regions $(440,450,461,474,500,517,527,551,582,607,622$ and $675 \mathrm{~nm})$ selected by interference optical light filters. The root-mean-square measurement error is $0.023 \mathrm{~m}^{-1}$.

Water samples were taken by the pump from the shaft going through the hull of the vessel, from $6 \mathrm{~m}$ depth (the lower edge of the shaft). Sampling was carried out both at stations and on the vessel's way.

A team of biologists from the Institute of Biology of the Southern Seas of the Academy of Sciences of Ukraine determined the concentration of chlorophyll $\left(C_{c h l}\right)$ in the samples.

\section{Characteristics of spectra}

The entire array containing 172 spectra is divided into three groups according to the beam attenuation coefficient on a wavelength of $500 \mathrm{~nm}$ : the first group (94 spectra $)-\varepsilon(500) \leq 0.15 \mathrm{~m}^{-1}$; the second one $(54$ spectra $)-0.15<\varepsilon(500) \leq 0.30 \mathrm{~m}^{-1}$; the third group $(24$ spectra $)-0.30<\varepsilon(500) \leq 0.45 \mathrm{~m}^{-1}$. The average concentration of 
chlorophyll according to the groups was: $0.03 ; 0.05$ and $0.31 \mathrm{mg} / \mathrm{m}^{3}$, i.e. the $1^{\text {st }}$ and $2^{\text {nd }}$ groups of spectra refer to the waters of the oligotrophic type (ocean waters), the third group - to the mesotrophic waters (coastal waters). Fig. 2 shows the average spectra in each group.

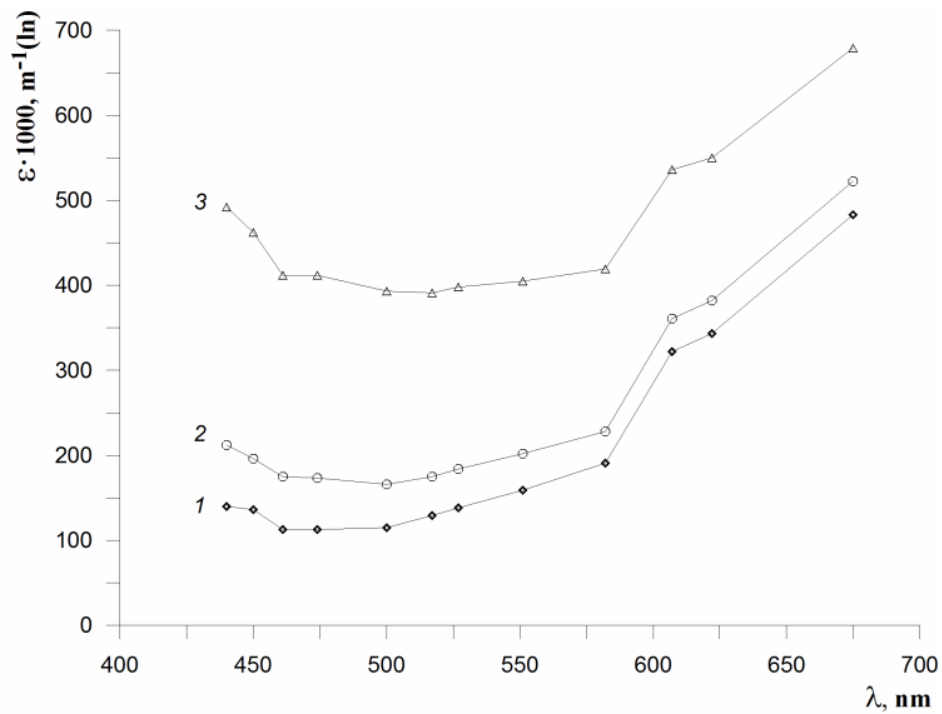

Fig. 2. Average spectra for three groups: $l(\diamond)-$ the $1^{\text {st }}$ group, $2(\mathrm{o})-$ the $2^{\text {nd }}$ group and $3(\Delta)-$ the $3^{\text {rd }}$ group of spectra

The spectra measured in the waters of large-scale NATR currents, including the coastal waters were selected from the entire array. These spectra are shown in Fig. 3. Their characteristics are given in Tab. 1.

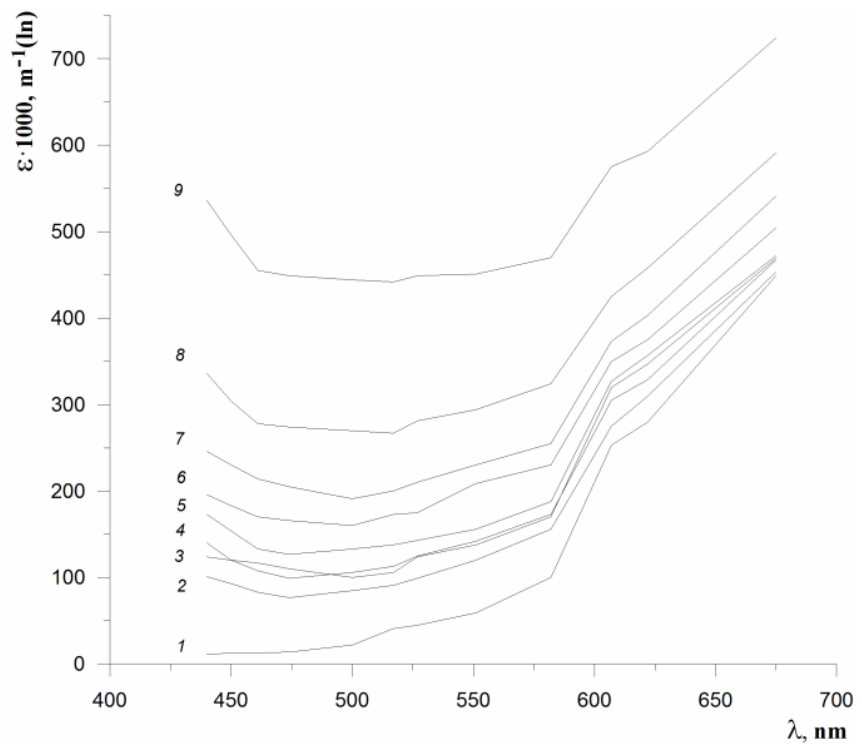

Fig. 3. Beam attenuation spectra in the waters of large-scale currents and in the coastal waters of the Atlantic tropical region: $1-9$ is the spectrum No. in Tab. 1 
Characteristics of the Spectra shown in Fig. 3, and Concentration of Chlorophyll in the Selected Samples

\begin{tabular}{|c|c|c|c|c|}
\hline $\begin{array}{l}\text { Spectrum } \\
\text { No. }\end{array}$ & Place of sampling & $\begin{array}{l}\text { Geographical } \\
\text { coordinates }\end{array}$ & $\begin{array}{c}\text { Beam attenuation } \\
\text { coefficient } \\
\varepsilon(500), \mathrm{m}^{-1}\end{array}$ & $\begin{array}{c}\text { Concentration } \\
\text { of Chlorophyll } \\
C_{c h l}, \mathrm{mg} / \mathrm{m}^{3} \\
\end{array}$ \\
\hline 1 & $\begin{array}{c}\text { Article [4] } \\
\text { (pure water) }\end{array}$ & - & 0.022 & 0.00 \\
\hline 2 & the Sargasso Sea & $\begin{array}{l}19^{\circ} 02^{\prime} \mathrm{N} \\
46^{\circ} 02^{\prime} \mathrm{W}\end{array}$ & 0.085 & 0.01 \\
\hline 3 & $\begin{array}{l}\text { The Betweenpassat } \\
\text { Counter Current }\end{array}$ & $\begin{array}{l}06^{\circ} 34^{\prime} \mathrm{N} \\
45^{\circ} 00^{\prime} \mathrm{W}\end{array}$ & 0.105 & 0.02 \\
\hline 4 & The Canary Current & $\begin{array}{l}27^{\circ} 31^{\prime} \mathrm{N} \\
17^{\circ} 50^{\prime} \mathrm{W}\end{array}$ & 0.100 & - \\
\hline 5 & The Guane Current & $\begin{array}{l}04^{\circ} 00^{\prime} \mathrm{N} \\
46^{\circ} 34^{\prime} \mathrm{W}\end{array}$ & 0.133 & 0.05 \\
\hline 6 & $\begin{array}{c}\text { The North Passat } \\
\text { Current }\end{array}$ & $\begin{array}{l}11^{\circ} 20^{\prime} \mathrm{N} \\
41^{\circ} 12^{\prime} \mathrm{W}\end{array}$ & 0.160 & 0.07 \\
\hline 7 & The Caribbean Sea & $\begin{array}{l}13^{\circ} 59^{\prime} \mathrm{N} \\
70^{\circ} 54^{\prime} \mathrm{W}\end{array}$ & 0.191 & - \\
\hline 8 & $\begin{array}{c}\text { Coastal } \\
\text { African waters }\end{array}$ & $\begin{array}{l}10^{\circ} 00^{\prime} \mathrm{N} \\
16^{\circ} 45^{\prime} \mathrm{W}\end{array}$ & 0.270 & 0.20 \\
\hline 9 & $\begin{array}{c}\text { Coastal } \\
\text { African waters }\end{array}$ & $\begin{array}{l}10^{\circ} 24^{\prime} \mathrm{N} \\
15^{\circ} 45^{\prime} \mathrm{W}\end{array}$ & 0.444 & 0.57 \\
\hline
\end{tabular}

The shape of the spectra in all the waters is characterized by the presence of a minimum of the beam attenuation coefficient in the middle part, from it towards the short and, especially intensively, towards the long waves, the values of $\varepsilon(\lambda)$ increase.

In the area of long waves, pure water makes a big contribution to the beam attenuation coefficient in all spectra. Fig. 3 shows the beam attenuation coefficient spectrum for pure water

$$
\varepsilon(\lambda)_{w}=\kappa(\lambda)_{w}+\sigma(\lambda)_{m w},
$$

where $\kappa(\lambda)_{w}$ is the pure water absorption index [4]; $\sigma(\lambda)_{m w}$ is the index of pure sea water molecular scattering [5, p. 157].

Tab. 2 shows the contribution of the pure sea water attenuation coefficient to the attenuation indices for the water spectra shown in Fig. 3. 


\section{Contribution of $\boldsymbol{P}$ Pure Sea Water Attenuation Coefficient to the Attenuation Indices $\varepsilon$ in the Atlantic Tropical Region}

\begin{tabular}{l|cc|c|c|c|c|c|c}
\hline \multirow{2}{*}{$\begin{array}{l}\text { Wavelength } \\
\lambda, \mathrm{nm}\end{array}$} & \multicolumn{8}{|c}{ Spectrum No. in Tab. } \\
\cline { 2 - 10 } & $\varepsilon, \mathrm{m}^{-1}$ & $P, \%$ & $\varepsilon, \mathrm{m}^{-1}$ & $P, \%$ & $\varepsilon, \mathrm{m}^{-1}$ & $P, \%$ & $\varepsilon, \mathrm{m}^{-1}$ & $P, \%$ \\
\hline 582 & 0.156 & 64 & 0.230 & 43 & 0.324 & 31 & 0.470 & 21 \\
622 & 0.310 & 90 & 0.375 & 75 & 0.458 & 61 & 0.593 & 41 \\
675 & 0.453 & 99 & 0.504 & 89 & 0.521 & 76 & 0.724 & 63 \\
\hline
\end{tabular}

As it can be seen from Fig. 3, when the attenuation indices increase, the shape of the spectra changes. It is due to a faster growth of $\varepsilon(\lambda)$ in the short-wave region than in the long-wave one. Thus, for the spectrum No. 9, the gain of the attenuation coefficient with respect to the spectrum No. 2 was: at a wavelength of $440 \mathrm{~nm}-$ $0.435 \mathrm{~m}^{-1}$ and at a wavelength of $675 \mathrm{~nm}-0.271 \mathrm{~m}^{-1}$.

At that, the minimum of the attenuation coefficient shifts towards the longer waves: the spectrum No. $2-\lambda\left(\varepsilon_{\min }\right)=474 \mathrm{~nm}$ and the spectrum No. $9-\lambda\left(\varepsilon_{\min }\right)=$ $=517 \mathrm{~nm}$. The water color is related to the minimum position, and in this case for the spectrum No. 2 it is characterized as a blue and for the spectrum No. 9 - as a green one.

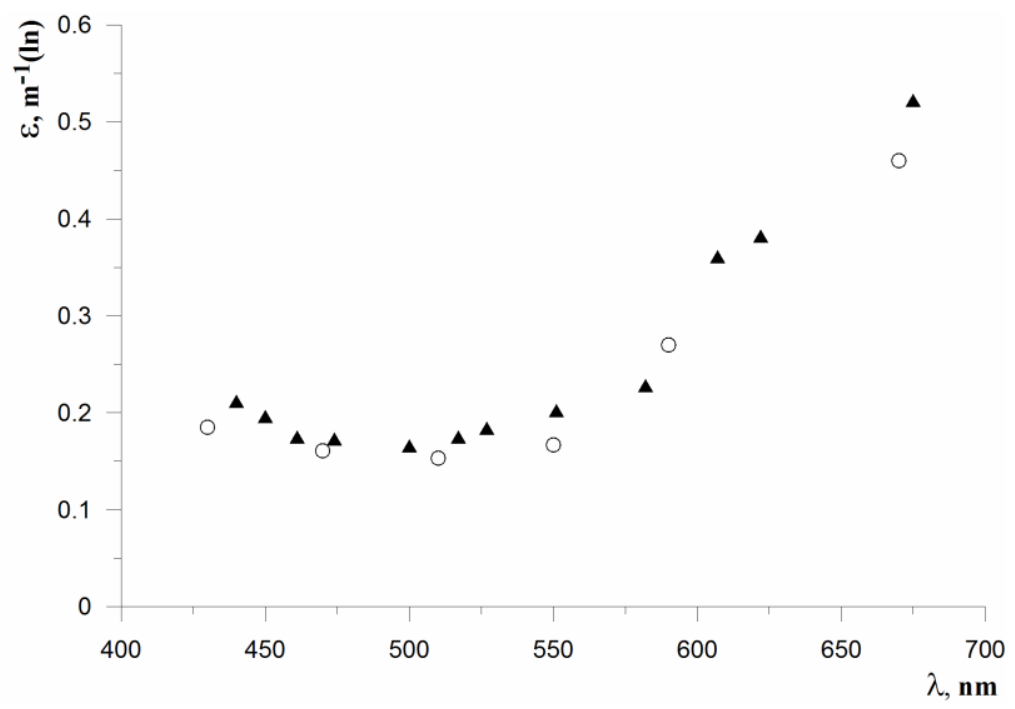

Fig. 4. Average spectra in oligotrophic waters of the Atlantic tropical region $(\mathbf{\Delta})$ and the Pacific Ocean (o)

Deformation of spectra with increasing of attenuation indices is associated with dissolved organic matter (DOM) content increase in water. This matter was formed as a result of the decomposition of plankton organisms, the concentration of which determines the water transparency. DOM most strongly attenuates the light in the short-wave part of the spectrum. Its influence weakly affects the longwave region [6]. 
Comparison of spectral characteristics of the attenuation coefficient in the waters of the NATR and the Pacific Ocean waters from [7] was carried out. The average spectrum (59 samples) in the ocean waters with depths less than $100 \mathrm{~m}$ with an average chlorophyll concentration of $0.027 \mathrm{mg} / \mathrm{m}^{3}$ is also taken from the aforementioned article. The average spectrum for the $2^{\text {nd }}$ group is taken for the NATR waters. The result of the comparison is shown in Fig. 4.

The nature of the spectral distribution of the attenuation coefficient in both cases is the same. The somewhat larger value of the spectral indices in the NATR waters agrees with the higher concentration of chlorophyll there, such as $0.050 \mathrm{mg} / \mathrm{m}^{3}$ in the NATR and $0.027 \mathrm{mg} / \mathrm{m}^{3}$ in the Pacific Ocean.

\section{Spectra analysis by the method of orthogonal vectors}

In each group of spectra, correlation matrices $R\left[\varepsilon\left(\lambda_{i}\right), \varepsilon\left(\lambda_{j}\right)\right]$ were calculated and the empirical functions of $\varepsilon(\lambda)$ were expanded into orthogonal eigenvectors:

$$
\varepsilon\left(\lambda_{i}\right)=\left\langle\varepsilon\left(\lambda_{i}\right)\right\rangle+\sum_{k=1}^{n} C_{k} \Psi_{k}\left(\lambda_{i}\right),
$$

where $\left\langle\varepsilon\left(\lambda_{i}\right)\right\rangle$ are the average values of the spectral attenuation coefficient; $\Psi_{k}\left(\lambda_{i}\right)$ are eigenvectors of the correlation matrix; $C_{k}$ are the specific coefficients; $i=1, \ldots, n$ is a number of vectors (in the present case $n=12$, the number of spectral channels).

Correlation matrices for different spectra types show that as the attenuation coefficient increases, the correlation coefficient between the values of $\varepsilon(\lambda)$ in different spectrum parts also increases; in the most cloudy waters (the $3^{\text {rd }}$ group) the variations of $\varepsilon(\lambda)$ are very closely interrelated in the entire wavelength range considered.

The same regularity of $R\left[\varepsilon\left(\lambda_{i}\right), \varepsilon\left(\lambda_{j}\right)\right]$ behavior was noted by the author of [8] from the $\varepsilon(\lambda)$ measurements within the wavelength range of $\lambda=390 \div 590 \mathrm{~nm}$ in the Indian Ocean. Thus, the values for the $1^{\text {st }}, 2^{\text {nd }}$ and $3^{\text {rd }}$ samples are $0.59 ; 0.75$ and 0.97 respectively [8]. For the $1^{\text {st }}, 2^{\text {nd }}$ and $3^{\text {rd }}$ groups of spectra considered in the present research, the range of $\varepsilon(\lambda)$ variation, approximately corresponding to the samples in [8], the values of $R[\varepsilon(440), \varepsilon(590)]$ are approximately the same: 0.61 ; 0.70 and 0.95 . I.e. the regularity of the attenuation coefficient variability in the World Ocean waters is the same.

As a result of the expansion of the $\varepsilon(\lambda)$ functions into orthogonal eigenvectors, it was obtained that the relative dispersion of the functions described by the first eigenvector is $0.78 ; 0.83$ and 0.98 for waters in the $1^{\text {st }}, 2^{\text {nd }}$ and $3^{\text {rd }}$ groups; and 0.80 ; 0.91 ; and 0.99 - for the sum of the first two eigenvectors, respectively.

The high relative dispersion value of $\varepsilon(\lambda)$ described by the expansion vector indicates the $\varepsilon(\lambda)$ variations by the spectrum to depend chiefly on one factor totally. The latter is known to be a biological suspension in an open ocean conditions. In this case it is confirmed by a high correlation coefficient of the chlorophyll concentration with the expansion coefficient for the first eigenvector, which is $R^{2}=$ $=0.87 \pm 0.02$ throughout the array. 
The high level of relative dispersion described by the first eigen vector, permits to reconstruct the spectral distribution of $\varepsilon(\lambda)$ in the surface tropical waters of the Atlantic Ocean from measurements of the beam attenuation coefficient in one part of the spectrum. Tab. 3 shows the necessary average values of the spectral beam attenuation coefficient $\left\langle\varepsilon\left(\lambda_{i}\right)\right\rangle$ and the first two orthogonal vectors $\Psi_{1}\left(\lambda_{i}\right), \Psi_{2}\left(\lambda_{i}\right)$.

The optimal wavelength that should be used to reconstruct the spectra by means of the first vector is situated in the region of zero values of the second orthogonal vector. According to Tab. 3 data, for the $1^{\text {st }}$ group of spectra is the wavelength range $\lambda=500 \div 517 \mathrm{~nm}$, for the $2^{\text {nd }}$ group $-\lambda=474 \div 500 \mathrm{~nm}$, for the $3^{\text {rd }}$ group $-\lambda=461 \div 474 \mathrm{~nm}$.

Table 3

\section{Average Values of the Beam Attenuation Coefficient $\langle\varepsilon\rangle$ and the First Two Orthogonal Vectors $\Psi_{1}, \Psi_{2}$ for Three groups of Spectra}

\begin{tabular}{|c|c|c|c|c|c|c|c|c|c|}
\hline \multirow{2}{*}{ 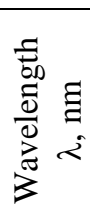 } & \multicolumn{3}{|c|}{$\begin{array}{l}1^{\text {st }} \text { group of spectra } \\
\varepsilon(500) \leq 0.15 \mathrm{M}^{-1}\end{array}$} & \multicolumn{3}{|c|}{$\begin{array}{c}2^{\text {nd }} \text { group of spectra } \\
0.15<\varepsilon(500) \leq 0.30 \mathrm{~m}^{-1}\end{array}$} & \multicolumn{3}{|c|}{\begin{tabular}{|c|}
$3^{\text {rd }}$ group of spectra \\
$0.30<\varepsilon(500) \leq 0.45 \mathrm{~m}^{-1}$ \\
\end{tabular}} \\
\hline & $\langle\varepsilon\rangle, \mathrm{m}^{-1}$ & $\Psi_{1}$ & $\Psi_{2}$ & $\langle\varepsilon\rangle, \mathrm{m}^{-1}$ & $\Psi_{1}$ & $\Psi_{2}$ & $\langle\varepsilon\rangle, \mathrm{m}^{-1}$ & $\Psi_{1}$ & $\Psi_{2}$ \\
\hline 440 & 0.140 & 0.283 & 0.329 & 0.212 & 0.297 & -0.342 & 0.492 & 0.306 & -0.228 \\
\hline 450 & 0.136 & 0.301 & 0.272 & 0.196 & 0.294 & -0.199 & 0.462 & 0.287 & -0.140 \\
\hline 461 & 0.113 & 0.251 & 0.197 & 0.175 & 0.289 & -0.105 & 0.412 & 0.265 & -0.037 \\
\hline 474 & 0.113 & 0.268 & 0.087 & 0.173 & 0.264 & -0.159 & 0.412 & 0.273 & 0.014 \\
\hline 500 & 0.115 & 0.234 & 0.033 & 0.166 & 0.266 & 0.078 & 0.393 & 0.259 & 0.124 \\
\hline 517 & 0.129 & 0.228 & -0.151 & 0.175 & 0.262 & 0.239 & 0.391 & 0.244 & 0.205 \\
\hline 527 & 0.138 & 0.234 & -0.123 & 0.184 & 0.253 & 0.190 & 0.398 & 0.244 & 0.197 \\
\hline 551 & 0.159 & 0.238 & -0.153 & 0.202 & 0.256 & 0.193 & 0.405 & 0.235 & 0.222 \\
\hline 582 & 0.191 & 0.257 & -0.350 & 0.228 & 0.222 & 0.300 & 0.419 & 0.205 & 0.315 \\
\hline 607 & 0.322 & 0.237 & -0.405 & 0.361 & 0.208 & 0.346 & 0.536 & 0.198 & 0.287 \\
\hline 622 & 0.343 & 0.250 & -0.314 & 0.382 & 0.190 & 0.336 & 0.550 & 0.187 & 0.289 \\
\hline 675 & 0.483 & 0.245 & -0.300 & 0.522 & 0.218 & 0.226 & 0.679 & 0.174 & 0.317 \\
\hline
\end{tabular}

Fig. 5 shows examples of the reconstruction of spectra from measurements of the beam attenuation coefficient at $500 \mathrm{~nm}$ wavelength. $\varepsilon\left(\lambda_{i}\right)$ values were calculated using the following formula

$$
\varepsilon\left(\lambda_{i}\right)=\left\langle\varepsilon\left(\lambda_{i}\right)\right\rangle+C_{1} \Psi_{1}\left(\lambda_{i}\right) .
$$

$C_{1}$ coefficient was defined from the condition below

$$
\varepsilon(500)=\langle\varepsilon(500)\rangle+C_{1} \Psi_{1}(500),
$$

where $\varepsilon(500)$ is the measured beam attenuation coefficient at $500 \mathrm{~nm}$ wavelength; $\langle\varepsilon(500)\rangle$ is the average value of beam attenuation coefficient for the given spectra array; $\Psi_{1}(500)$ is the first orthogonal vector. 


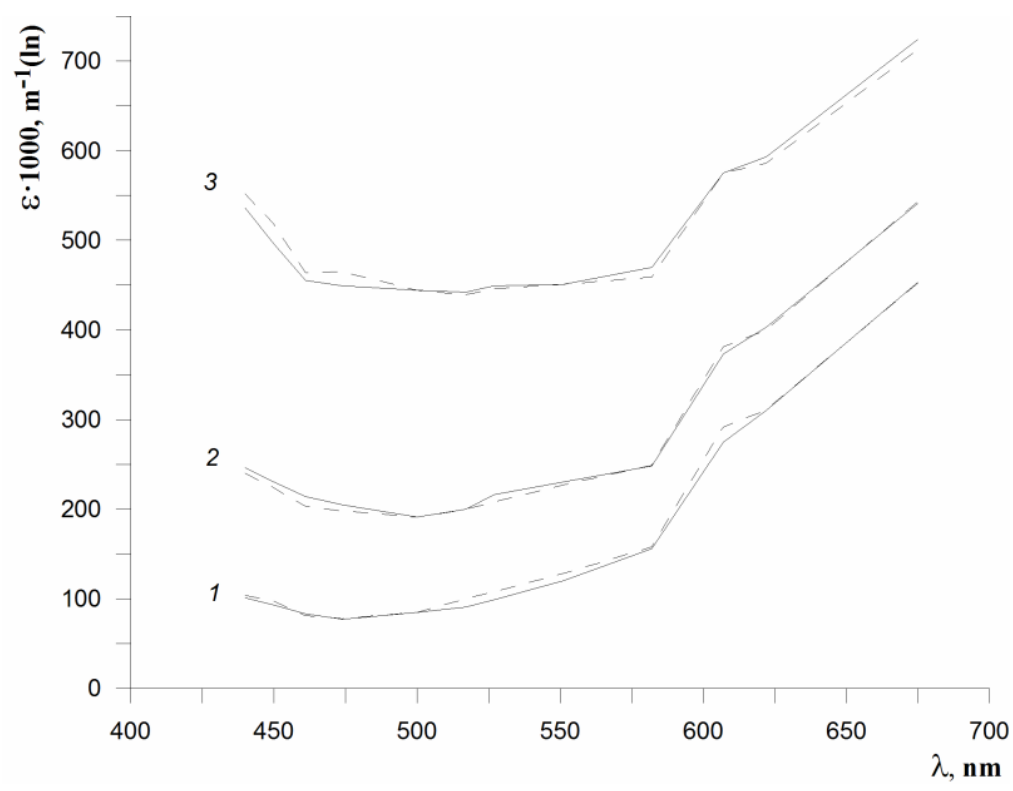

Fig. 5. Examples of spectra reconstructing using the first orthogonal vector from measurements of beam attenuation coefficient at $500 \mathrm{~nm}$ wavelength: measured spectra $(-)$, reconstructed spectra $(--) ; 1,2,3-$ the groups of spectra

The error estimation of the representation of the $\varepsilon(\lambda)$ functions by the eigenvectors was carried out by the formula below

$$
S_{m}=\left[1 / n \cdot \delta^{2}(n-m) \sum_{n} D(\lambda)\right]^{0,5},
$$

where $n$ is the number of all vectors in the analysis; $m$ is the number of vectors used for $\varepsilon(\lambda)$ reconstruction; $D(\lambda)$ is the standard deviation of $\varepsilon(\lambda)$ function; $\delta(n-m)$ is the relative dispersion of the eigenvectors, which are not used in the reconstruction.

Ta ble 4

Deviation Indices of $\varepsilon_{\text {rec }}$ Spectra Reconstructed by the First Orthogonal Vector from the Measured $\varepsilon_{\text {meas }}$ Spectra

\begin{tabular}{c|c|c|c}
\hline $\begin{array}{c}\text { Group of } \\
\text { spectra }\end{array}$ & $\begin{array}{c}R m s \text { deviation } \sigma_{\text {rec }}, \\
\mathrm{m}^{-1}\end{array}$ & $\begin{array}{c}\text { Max deviation } \\
\varepsilon_{\text {rec }}-\varepsilon_{\text {meas }}, \mathrm{m}^{-1}\end{array}$ & $\begin{array}{c}\text { Max relative } \\
\text { deviation } \\
\varepsilon_{\text {rec }} / \varepsilon_{\text {meas }} \%\end{array}$ \\
\hline $1^{\text {st }}$ & 0.006 & 0.017 & 1.06 \\
$2^{\text {nd }}$ & 0.005 & -0.011 & 0.95 \\
$3^{\text {rd }}$ & 0.011 & 0.022 & 1.04 \\
\hline
\end{tabular}

For the $1^{\text {st }}, 2^{\text {nd }}$ and $3^{\text {rd }}$ groups of spectra the $S_{m}$ value for $m=1$ was 0.012 ; 0.014 and $0.023 \mathrm{~m}^{-1}$ respectively.

Tab. 4 shows deviation indices of the reconstructed spectra from the measured ones. The rms errors were $0.006 ; 0.005$ and $0.011 \mathrm{~m}^{-1}$ for the $1^{\text {st }}, 2^{\text {nd }}$ and $3^{\text {rd }}$ groups respectively, as is obvious they do not exceed the theoretical values. 
Relationship between spectral beam attenuation coefficients and chlorophyll concentration

Tab. 1 demonstrates $C_{c h l}$ chlorophyll concentration in water for the spectra in Fig. 3. A quantitative relationship between the quantities $\varepsilon(500)$ and $C_{c h l}$ is clear.

The data analysis showed the relationship between these quantities to be nonlinear and in a linear form it can be represented in a double logarithmic scale

$$
\lg C_{c h l}=A \lg \varepsilon(\lambda)+B .
$$

During the calculation of the regression coefficients, the data was divided into two arrays: the ocean and coastal waters. It was due to the fact that the ratios $C_{c h l}=f[\varepsilon(\lambda)]$ in the ocean and coastal waters are different (Fig. 6).

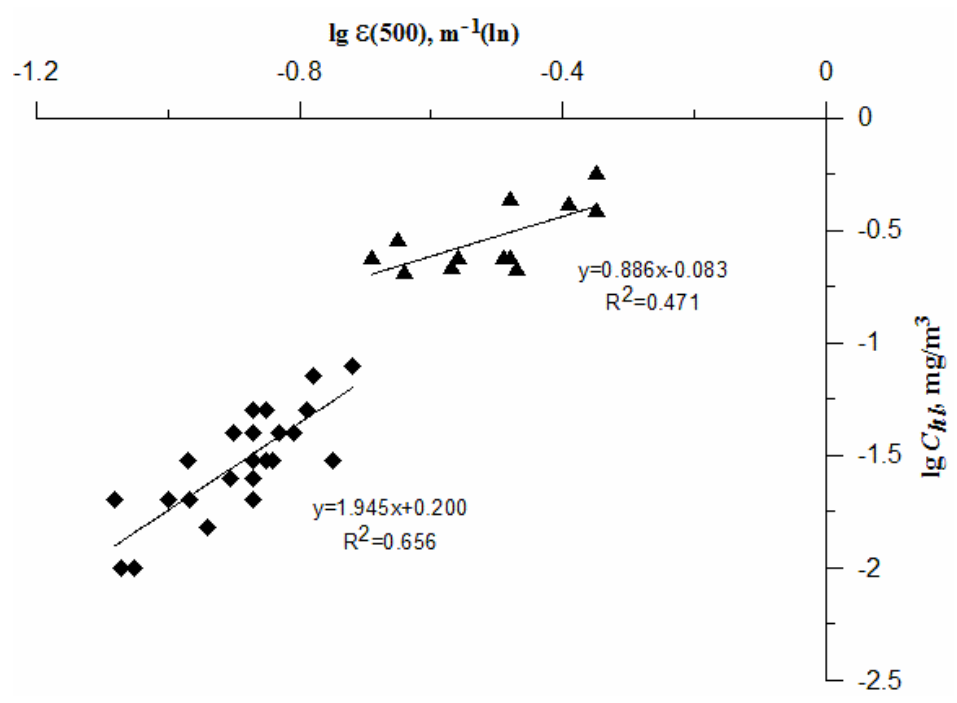

Fig. 6. Relationship between chlorophyll concentration and beam attenuation coefficient at $500 \mathrm{~nm}$ wavelength in the ocean $(\bullet)$ and coastal $(\boldsymbol{\Delta})$ waters

Tab. 5 shows the results of calculations of regression coefficients of chlorophyll concentration for the ocean waters are presented (the variability range is $C_{c h l}=0.01 \div 0.08 \mathrm{mg} / \mathrm{m}^{3}$ ) with spectral beam attenuation coefficients in three spectral regions: 440,500 and $551 \mathrm{~nm}$.

Table 5

Coherence Coefficients of $\lg C_{c h l}=A \lg \varepsilon(\lambda)+B$ in the Ocean Waters, $R$ Correlation Coefficient, its $\delta R$ Error and $S\left(C_{c h l}\right)$ Chlorophyll Concentration Definition Error

\begin{tabular}{c|cc|c|c}
\hline \multirow{2}{*}{$\begin{array}{c}\text { Wavelength } \\
\lambda, \mathrm{nm}\end{array}$} & \multicolumn{2}{|c|}{ Coherence Coefficients } & \multirow{2}{*}{$R(\delta R)$} & \multirow{2}{*}{$S\left(C_{\text {chl }}\right), \mathrm{mg} / \mathrm{m}^{3}$} \\
\cline { 2 - 3 } & $A$ & $B$ & & \\
\hline 440 & 1.99 & 0.05 & $0.81(0.08)$ & 0.008 \\
500 & 1.94 & 0.20 & $0.81(0.08)$ & 0.008 \\
551 & 2.51 & 0.42 & $0.85(0.07)$ & 0.007 \\
\hline
\end{tabular}


The chlorophyll concentration correlation with the beam attenuation coefficient reflects the relationship with the attenuation index of the organic suspended matter. The organic suspended matter in surface ocean waters makes an overwhelming contribution to the variability of the attenuation coefficient, which, according to the data of [7], is 76-97\% in the spectral range of $430-670 \mathrm{~nm}$.

Different relations in the association equations of chlorophyll with the attenuation coefficient in ocean and coastal waters, observed in the present case (Fig. 6), are associated with a change in the intracellular chlorophyll concentration in algae, depending on a number of the following factors: species composition, light habitat, water temperature and content of nutrients. In [9] it has been established that under identical conditions the chlorophyll concentration in cells of diatoms and pyrophyte algae can differ by a factor of two. In [10], graphs of the chlorophyll and suspended organic matter (SOM) relation in the Black Sea waters in different seasons are presented. In spring, the SOM concentration is approximately twice higher than in winter, at the same chlorophyll concentration in water.

I.e. the chlorophyll concentration and attenuation coefficient relations possess regional nature and may vary in time in the given area due to changes in the algae habitat conditions.

Taking this into consideration, the chlorophyll concentration and attenuation coefficient relations in the NATR ocean waters, established in this work, should be characterized as the regional ones. The hydrological conditions in tropical waters vary slightly throughout the year, and these relations can be presumably assumed to be unchanged in time.

Formulae of $C_{c h l}=f[\varepsilon(\lambda)]$ relation, obtained for the NATR waters, were applied to the other ocean waters. The mean spectrum of $\varepsilon(\lambda)$ for oligotrophic ocean waters of the Pacific Ocean with an average chlorophyll concentration $C_{c h l}=0.027 \mathrm{mg} / \mathrm{m}^{3}$ is taken from [7]. Tab. 6 shows the chlorophyll concentration values in the NATR waters (the $2^{\text {nd }}$ group of spectra, $C_{c h l}=0.050 \mathrm{mg} / \mathrm{m}^{3}$ ) and the Pacific Ocean calculated according to the Tab. 5 formulae.

Table 6

$C_{c h l}$ Chlorophyll Concentration Values Calculated according to Tab. 5 Formulae for the Mean Spectra in the Atlantic (54 samples, $\left.\left\langle C_{c h l}\right\rangle=0.050 \mathrm{mg} / \mathrm{m}^{3}[7]\right)$ and Pacific Ocean (59 samples, $\left\langle C_{c h l}\right\rangle=0.027 \mathrm{mg} / \mathrm{m}^{3}[7]$ )

\begin{tabular}{c|cc|c|c}
\hline \multirow{2}{*}{$\begin{array}{c}\text { Wavelength } \\
\lambda, \mathrm{nm}\end{array}$} & \multicolumn{2}{|c|}{ The Atlantic Ocean } & \multicolumn{2}{c}{ The Pacific Ocean } \\
\cline { 2 - 5 } & $\varepsilon(\lambda), \mathrm{m}^{-1}$ & $C_{c h l}, \mathrm{mg} / \mathrm{m}^{3}$ & $\varepsilon(\lambda), \mathrm{m}^{-1}$ & $C_{c h l}, \mathrm{mg} / \mathrm{m}^{3}$ \\
\hline 440 & 0.212 & 0.051 & 0.184 & 0.039 \\
500 & 0.166 & 0.049 & 0.153 & 0.041 \\
551 & 0.202 & 0.047 & 0.169 & 0.030 \\
\hline \multicolumn{4}{c}{$<0.049>*$} \\
\hline
\end{tabular}

$*<\ldots>-$ average value

The chlorophyll concentrations in different waters in the Pacific Ocean calculated according to different formulae gave an average value of $C_{c h l}=0.037 \mathrm{mg} / \mathrm{m}^{3}$. It is $37 \%$ higher than that indicated in [7]. The closest result was obtained for $551 \mathrm{~nm}$ wavelength $\left(C_{c h l}=0.030 \mathrm{mg} / \mathrm{m}^{3}\right)$. In the NATR waters 50 
(the $2^{\text {nd }}$ group of spectra), the calculated average chlorophyll concentration $C_{c h l}=0.049 \mathrm{mg} / \mathrm{m}^{3}$ is practically the same as for field observations $\left(C_{c h l}=0.050 \mathrm{mg} / \mathrm{m}^{3}\right)$.

In [11], the relation between the attenuation coefficient and the chlorophyll concentration in the Pacific Ocean tropical waters has been studied. The research area was situated in the eastern part of the near-equatorial region $\left(10^{\circ} \mathrm{N}-10^{\circ} \mathrm{S}\right)$. To establish the relations with chlorophyll, the sea water attenuation coefficient at $660 \mathrm{~nm}$ wavelength was used. The pure water attenuation coefficient $\varepsilon(660)_{p g}=$ $=\varepsilon(660)_{\text {measured }}-\varepsilon(660)_{w}$ was subtracted from this coefficient. The calculation of the coupling equation was carried out with $C_{c h l}$ and $\varepsilon(660)_{p g}$ values in natural form without conversion. The chlorophyll concentration in the research waters varied within the values of $C_{c h l}=0.02 \div 0.32 \mathrm{mg} / \mathrm{m}^{3}$. All the data, without separation by chlorophyll concentration, are combined into one array, and the coupling equation is calculated (correlation coefficient $R=0.91$ ):

$$
C_{c h l}=2.6 \varepsilon(660)_{p g}-0.014 \text {. }
$$

It should be noted that in the aforementioned work [11, p. 441] on the graph (Fig. 4C), a group of points for the waters with the lowest chlorophyll concentrations, $C_{c h l}=0.02 \div 0.07 \mathrm{mg} / \mathrm{m}^{3}$, is distinguished. I.e. as in the case of the ocean oligotrophic waters of the tropical Atlantic, in the same Pacific Ocean waters, there is only a relation between chlorophyll and the attenuation coefficient appropriate for this area.

\section{Conclusion}

According to the data of the beam attenuation coefficient spectra measurements in the surface waters of the tropical Atlantic northern part, the characteristics of the spectra $(440-675 \mathrm{~nm}$ range) were obtained. Also, the change of the spectra shape the in the NATR waters with the attenuation coefficient increase was considered. Spectral distributions of the attenuation coefficient in the waters of the principal large-scale NATR currents and in the coastal African waters are presented. A comparison of the mean spectra in oligotrophic waters of the tropical Atlantic and the Pacific Ocean was carried out. It showed the same pattern of the spectral distribution of the attenuation coefficient in these regions.

For an array of empirical functions $\varepsilon(\lambda)$ in the NATR waters, the expansion into orthogonal eigenvectors was carried out. The possibility to reconstruct the spectra using the first orthogonal vector, i.e. by measuring the attenuation coefficient at one wavelength, is shown. The optimal wavelength values, which should be used to reconstruct the spectra, are indicated.

The relation of the chlorophyll concentration in the surface ocean waters of the NATR with the beam attenuation coefficients in three sections of the spectrum with wavelengths of 440, 500 and $551 \mathrm{~nm}$ was established. In the NATR coastal waters the relation $C_{c h l}=f[\varepsilon(\lambda)]$ should be considered separately, since it differs significantly from the one in ocean waters. The chlorophyll and attenuation coefficient relations in NATR ocean waters established in this work should be characterized as regional.

Acknowledgements. The present article was carried out within the framework the state order No. 0827-2014-0010. 


\section{REFERENCES}

1. Pavlov, V.M., 1974. Prozrachnost' Morskoy Vody [Sea Water Transparency]. In: A.S. Monin, K.S. Shifrin eds.,1974. Gidrofizicheskie i Gidroopticheskie Issledovaniya v Atlanticheskom $i$ Tikhom Okeanakh: Po Resultatam Issledovaniy v 5om Reise NIS "Dmitriy Mendeleev" [Hydrophysical and Hydrooptical Research in the Atlantic and Pacific Oceans: According to the Research Results in the $5^{\text {th }}$ Cruise of R/V Dmitriy Mendeleyev]. Moscow: Nauka, pp. 127139 (in Russian).

2. Li, M.E. and Mankovsky, V.I., 2004. Gidroopticheskie Issledovaniya Morey i Okeanov. Tropicheskaya Zona Atlanticheskogo Okeana [Hydrooptical Studies of the Seas and Oceans. The Atlantic Ocean Tropical Zone]. In: V.N. Eremeev ed., 2004. Razvitie Morskikh Nauk $i$ Tekhnologiy v Morskom Gidrofizicheskom Institute NAN Ukrainy za 75 let [The Development of Marine Sciences and Technologies in the Marine Hydrophysical Institute of NAS of Ukraine for 75 Years]. Sevastopol: ECOSI-Gidrofizika, pp. 268-298 (in Russian).

3. Mankovsky, V.I., 2012. Spektral'nyy Laboratornyy Prozrachnomer s Peremennoy Bazoy [Spectral Laboratory Transparency Meter with Variable Base]. In: Sistemy Kontrolya Okruzhayushchey Sredy [Environmental Control Systems]. Sevastopol: MHI. Iss. 17, pp. 5660 (in Russian).

4. Pope, R.M. and Fry, E.S., 1997. Absorption Spectrum (380-700 nm) of Pure Water. II. Integrating Cavity Measurements. Appl. Optics, [e-journal 36(33), pp. 8710-8723. https://doi.org/10.1364/AO.36.008710

5. Kopelevich, O.V., 1983. Faktory, Opredelyayushchie Opticheskie Svoystva Morskoy Vody [Factors Determining the Marine Environment optical Properties]. In: A.S. Monin ed., 1983. Optika Okeana. T. 1. Fizicheskaya Optika Okeana [Optics of the Ocean. Vol. 1, Physical Optics of the Ocean]. Moscow: Nauka Publ., pp. 150-166 (in Russian).

6. Kopelevich, O.V., 1983. Rastvorennye Organicheskie Veshchestva [Dissolved Organic Matters]. In: A.S. Monin ed., 1983. Optika Okeana. T. 1. Fizicheskaya Optika Okeana [Optics of the Ocean. Vol. 1, Physical Optics of the Ocean]. Moscow: Nauka Publ., pp. 157-160 (in Russian).

7. Kopelevich, O.V., 1983. Maloparametricheskaya Model' Opticheskikh Svoystv Morskoy Vody [A small Parametric Model of the Optical Properties of Sea Water]. In: A.S. Monin ed., 1983. Optika Okeana. T. 1. Fizicheskaya Optika Okeana [Optics of the Ocean. Vol. 1, Physical Optics of the Ocean]. Moscow: Nauka Publ., pp. 208-234 (in Russian).

8. Kopelevich, O.V., 1982. "Vosstanovlenie" Spektral'nykh Velichin Pokazatelei Oslableniya Sveta Morskoy Vodoy v Oblasti 270-590 nm po Dannym Izmereniy dlya Dvukh Dlin Voln [Calculation of the Spectral Values of the Sea Water Light Attenuation Coefficient in the Spectral Region of 270-590 nm from the Measured Values for Two Wave Lengths]. Okeanologiya, 22(3), pp. 392-397 (in Russian).

9. Finenko, Z.Z., Hoeppfner, N., Williams, R. and Piontkovski, S.A., 2003. Phytoplankton Carbon to Chlorophyll a Ratio: Response to Light, Temperature and Nutrient Limitation. Marine Ecological Journal, 2(2), p. 40-64.

10. Kukushkin, A.S., 2012. Mnogoletnyaya i Sezonnaya Izmenchivost' Soderzhaniya Vzveshennogo Organicheskogo Veshchestva v Verkhnem Sloe v Glubokovodnykh Rayonakh Chernogo Morya [Long-Term and Seasonal Variability of the Suspended Organic Matter Content in the Upper Layer in the Deep Waters of the Black Sea]. In: V.N. Eremeev, S.K. Konovalov eds., 2012. Ustoychivost' $i$ Evolyutsiya Okeanologicheskikh Kharakteristik Ekosistemy Chernogo Morya [The Stability and Evolution of the Oceanographic Characteristics of the Black Sea Ecosystem]. Sevastopol: ECOSI-Gidrofizika, pp. 242-263 (in Russian).

11. Behrenfeld, M.J. and Boss, E., 2006. Beam Attenuation and Chlorophyll Concentration as Alternative Optical Indices of Phytoplankton Biomass. J. Mar. Res., [e-journal] 64(3), pp. 431-451. https://doi.org/10.1357/002224006778189563 